\title{
Morphology of Imidazolium-Based lonic Liquids as Deposited by Vapor Deposition: Micro-/Nanodroplets and Thin Films
}

\author{
José C. S. Costa, ${ }^{*}[a, b]$ Adélio Mendes, ${ }^{[b]}$ and Luís M. N. B. F. Santos ${ }^{*}[a]$
}

[a] Dr. J. C. S. Costa, Prof. L. M. N. B. F. Santos Centro de Investigação em Química (CIQ) Departamento de Química e Bioquímica Faculdade de Ciências, Universidade do Porto Rua do Campo Alegre, 687, 4169-007 Porto (Portugal)

E-mail: josecdscosta@gmail.com Ibsantos@fc.up.pt

[b] Dr. J. C. S. Costa, Prof. A. Mendes

Laboratory for Process Engineering, Environment, Biotechnology and Energy (LEPABE) Faculdade de Engenharia, Universidade do Porto Rua Dr. Roberto Frias, 4200-465 Porto (Portugal)

The morphology of micro- and nanodroplets and thin films of ionic liquids (ILs) prepared through physical vapor deposition is presented. The morphology of droplets deposited on indium-tinoxide-coated glass is presented for the extended 1-alkyl-3-methylimidazolium bis(trifluoromethylsulfonyl)imide $\left(\left[\mathrm{C}_{n} \mathrm{C}_{1} \mathrm{im}\right]\left[\mathrm{Ntf}_{2}\right] ; \mathrm{n}=1-8\right)$ series, and the results show the nanostructuration of ILS. The use of in-vacuum energetic particles enhances/increases the nanodroplets mobility/coalescence mechanisms and can be a pathway to the fabrication of thin IL films.

Ionic liquids (ILS) are a family of materials that offer a range of properties that can be adjusted to optimize their performance in a diversity of technological applications. ${ }^{[1-3]}$ ILs share common characteristics, such as ionic conductivity, good thermal stability, and extremely low vapor pressure at room temperature. ${ }^{[4-6]}$ In recent years, extensive studies of the thermo-physical properties of ILs have shown that almost none of these properties are shared across the IL range due to structural/nanostructural modifications. ${ }^{[7-9]} \mathrm{ILs}$ are becoming particularly attractive for many applications, such as solvents for electro-chemistry (electrically conducting fluids, electrolytes), sealants, chemical industry, gas handling, pharmaceuticals, cellulose processing, dye-sensitized solar cells, waste recycling, batteries, dispersion of nanomaterials, and electrode-electrolyte interfaces in high-vacuum systems. ${ }^{[10-15]}$

Recently, the liquid/vacuum and liquid/solid interfaces of ILs have been of great relevance for most of the above-mentioned applications, and model surface studies and molecular orientation/ordering investigations of ILs have been performed on surfaces with different chemical properties: $\mathrm{Au}, \mathrm{Ni}$, silica, graphene, alumina, glass, and mica. ${ }^{[16-20]}$ In some cases, thin films of ILs have been prepared by using impregnation techniques with solutions of ILs in volatile solvents, followed by solvent removal by evaporation. Thus, nanostructures of ILs can be prepared by spin/dip-coating methods and the films have low thicknesses and exceptional lubrication characteristics. ${ }^{[20]}$ In recent years, the focus has been on physical vapor deposition (PVD) of ILs on different surfaces ${ }^{[16,18,19]}$ 
Herein, we present the morphology of micro- and nanodroplets of a class of imidazolium-based ILs, the 1-alkyl-3-methyli-midazolium bis(trifluoromethylsulfonyl)imide $\left(\left[\mathrm{C}_{n} \mathrm{C}_{1} \mathrm{im}\right]\left[\mathrm{Ntf}_{2}\right]\right)$ series, prepared by thermal evaporation and subsequent condensation under high-vacuum conditions by using a multilayer thin film vapor deposition apparatus, ThinFilmVD, recently developed in our laboratory. ${ }^{[21]}$ This apparatus, based on Knudsen cells with an accurate mass flow control, $\mathrm{m} /(\mathrm{At})$, was designed to assemble well-defined nanostructures of organic semiconductors (OSCs) based on their volatility. At a temperature $T$, the mass $m$ of the sample sublimed/vaporized from the Knudsen cell, during the time period $t$, is related to the vapor pressure $p$ of the compound according to Equation (1):

$$
\frac{m}{A_{\mathrm{o}} t}=\frac{p w_{\mathrm{o}} M^{1 / 2}}{(2 \pi R T)^{1 / 2}}
$$

$M$ is the molar mass of the vapor, $R$ is the gas constant, $A_{o}$ is the area of the effusion orifice and $\mathrm{W}_{\mathrm{o}}$ is the transmission probability factor. ${ }^{[21]}$ Figure 1 depicts the morphology of micro- and nanodroplets prepared with a real-time mass flow rate of ap-proximately $3 \mathrm{ng}\left(\mathrm{cm}^{2} \mathrm{~s}\right)^{-1}$ onto an ITO surface. The mass flow rate/thickness evaluation and control was determined by using a quartz crystal microbalance (QCM) located near the substrate support (located at the same distance from the effusion orifice, $\approx 10 \mathrm{~cm}$ ).
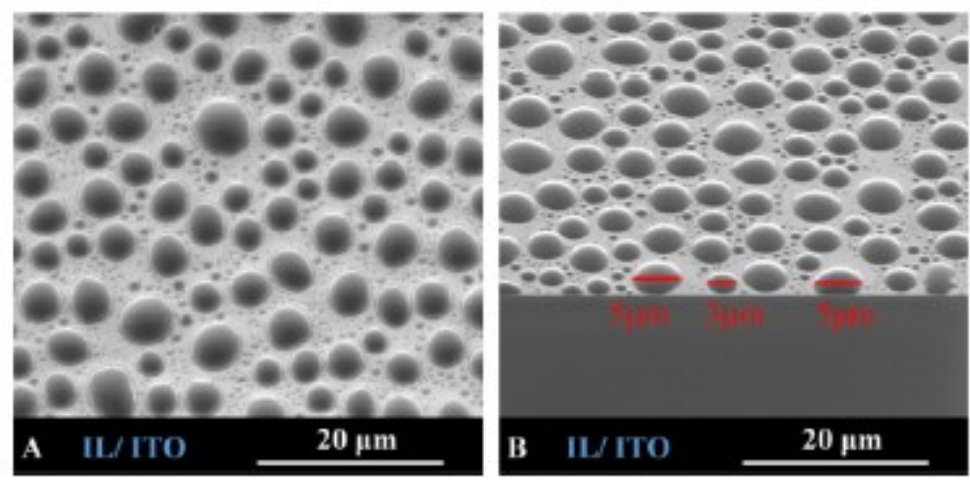

Figure 1. SEM images (5000x) of micro- and nanodroplets of IL ([C3C1im] [Ntf2]) deposited on an ITO-coated glass surface by PVD: A) Topview, B) cross-sectional view.

The PVD techniques are more environmentally friendly than traditional coating methods, with several applications from scientific and industrial points of view. In fact, thin films produced by PVD are being developed and applied in electrical and semiconductor manufactories, for example, in organic electronics and optoelectronics (OLEDs, OPVs, OFETs), and used for energy conservation and/or generation. ${ }^{[22-24]}$ The ThinFilmVD system allows accurate vapor-pressure measurements and high versatility for the deposition of single thin films, as-grown crystals, composites, and hybrid micro- and nanostructured materials. ${ }^{[21]}$

High-accuracy vapor-pressure data for the extended $\left[\mathrm{C}_{n} \mathrm{C}_{1} \mathrm{im}\right]\left[\mathrm{Ntf}_{2}\right]$ ionic liquid series were determined by Santos et al. by using a Knudsen effusion apparatus combined with a QCM and the authors contributed for a better understanding of the relationship between cohesive energies, volatilities, and liquid structures of ILs. ${ }^{[25]}$ Recently, there have been other groups who have started using a QCM and PVD to measure vapor pressures of ILs and prepare ultrathin IL films by using vapor deposition techniques. ${ }^{[26-28]}$ The trend shifts observed for the thermodynamic properties of vaporization of the $\left[\mathrm{C}_{n} \mathrm{C}_{1} \mathrm{im}\right]\left[\mathrm{Ntf}_{2}\right]$ IL series, which occur at $\left[\mathrm{C}_{6} \mathrm{C}_{1} \mathrm{im}\right]\left[\mathrm{Ntf}_{2}\right]$ (the CAS, or critical alkyl size), are evidence of the nanostructuration of ILs. 
Another important contribution, presented by Coutinho et al., has shown that the surface tension of this class of ionic liquids decreases with an increase in the cation alkyl side chain size up to aliphatic chains no longer than hexyl, labeled as the CAS. For ILs with aliphatic moieties longer than the CAS, the surface tension displays an almost constant value up to $\left[\mathrm{C}_{16} \mathrm{C}_{1}\right.$ im] $\left[\mathrm{NTf}_{2}\right]$. The same trend was found in the relative cation-anion interaction energies measured by using mass spectrometry, which indicates the importance of the cohesive forces in the surface organization of ILs. ${ }^{[29]}$

For this work, IL nanostructures were deposited onto an indium tin oxide (ITO)-coated glass surface by using vacuum deposition and controlling the mass flow from a thermally regulated Knudsen cell.

For this purpose, each compound $\left(\left[\mathrm{C}_{n} \mathrm{C}_{1} \mathrm{im}\right]\left[\mathrm{Ntf}_{2}\right]\right.$ IL series, $\left.\mathrm{n}=1-8\right)$ was vaporized at a vapor pressure of $p=0.1 \mathrm{~Pa}^{[25]}$ (real-time mass flow rate of $\approx 3 \mathrm{ng}\left(\mathrm{cm}^{2} \mathrm{~s}\right)^{-1}$ was controlled by a QCM for all compounds). Effusion times of 15, 30, and 60 min were applied and the ITO surface was maintained at $\mathrm{T}=293 \mathrm{~K}$. The morphology of the nanostructures was explored by using highresolution scanning electron microscopy (SEM). Detailed data is presented as Supporting Information. As shown, micro- and nanodroplets of ILs (precursor films) were deposited by a PVD methodology (Figure 2).

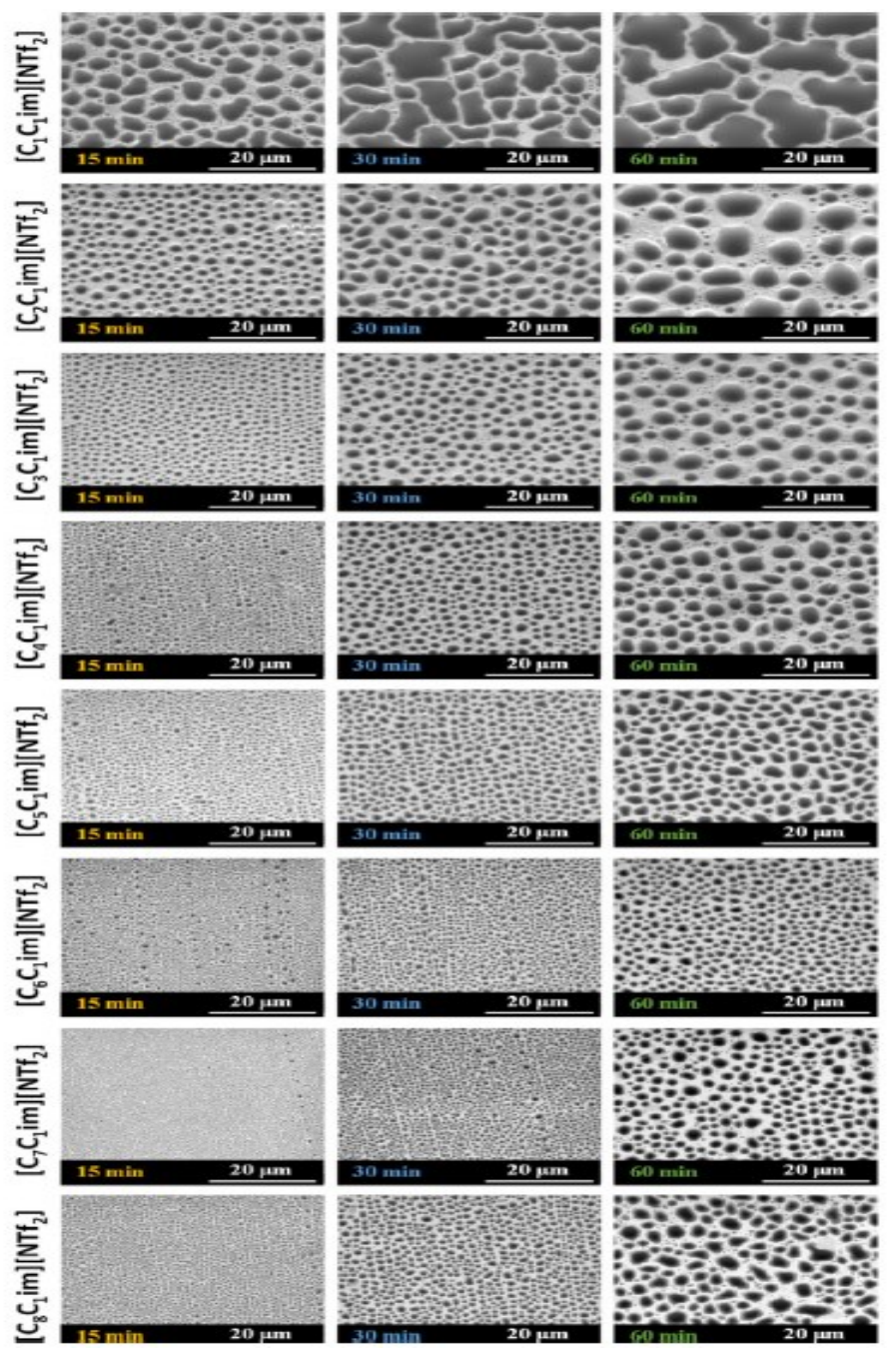

Figure 2. SEM images $(5000 \mathrm{x})$ of nanostructures of ILs ([ $\mathrm{C}_{n} \mathrm{C}_{1}$ im] $]\left[\mathrm{Ntf}_{2}\right]$ series) deposited with the same mass flow rate on the ITO-coated glass surface by PVD after deposition times of 15, 30 and $60 \mathrm{~min}$. 
According to previous literature reports on PVD IL films under ultra-high vacuum conditions on many solid surfaces, depending on chemical nature of the IL and the support, a layer-by-layer growth, wetting-layer followed by island growth, and pure island-growth models can be observed for IL nanostructures. ${ }^{[27,30-33]}$ Due to their low vapor pressure, ILs are candidates for precursor film studies and the first study of pre-cursor films spreading ahead of macroscopic droplets of imidazolium-based ILs (on smooth mica surfaces) was carried out by Beattie et al. ${ }^{[34]}$ Additionally, in recent literature reports there are several publications dedicated to interfacial tension studies, including the measurement of contact angles formed by various ILs on different solid substrates. ${ }^{[35-37]}$ ILs are being considered as electrolytes in several energy applications, thus the wetting characteristics of the IL in contact with a solid substrate are critically important. ${ }^{[38,}$ 39] The $\left[\mathrm{C}_{n} \mathrm{C}_{1} \mathrm{im}\right]\left[\mathrm{Ntf}_{2}\right]$ IL series was deposited onto the ITO surface, one of the most widely used transparent conducting oxides with direct application as an electrode in organic/inorganic electronic devices. ${ }^{[40,41]}$

According to the topographic images, the size and the number of droplets on the ITO surface are not shared across the IL range. For example, concerning all ILs studied, under the same experimental conditions $\left[\mathrm{C}_{1} \mathrm{C}_{1} \mathrm{im}\right]\left[\mathrm{Ntf}_{2}\right]$ exhibits the lowest number of droplets formed but each nano/microstructure presents on average a higher size. On increasing the chain size, the number of droplets formed is successively increased. For all ILs, higher deposition times led to a decrease in the number of droplets per unit area and the size of each droplet was increased. According to the nucleation, diffusion, and growth mechanisms of thin films, this experimental observation reveals the process of cluster coalescence. ${ }^{[42,43]}$

To enable a comparison between all results, Figure $3 \mathrm{~A}$ presents a schematic representation of the number of droplets formed per $\mathrm{mm}^{2}$ of surface area and Figure $3 \mathrm{~B}$ presents the surface occupation (surface coverage) percentage as a function of each IL of the $\left[\mathrm{C}_{n} \mathrm{C}_{1} \mathrm{im}\right]\left[\mathrm{Ntf}_{2}\right]$ series. These data was explored in the SEM images $(500 \mathrm{x})$ by using image processing in the ImageJ software (see the Supporting Information).

According to Figure 3 , for a deposition time of $30 \mathrm{~min}$, the number of droplets formed increases linearly between $\left[\mathrm{C}_{1} \mathrm{C}_{1} \mathrm{im}\right]\left[\mathrm{Ntf}_{2}\right]$ and $\left[\mathrm{C}_{6} \mathrm{C}_{1} \mathrm{im}\right]\left[\mathrm{Ntf}_{2}\right]\left(\mathrm{r}^{2}=0.9993\right)$. A trend shift clearly occurs at $\left[\mathrm{C}_{6} \mathrm{C}_{1} \mathrm{im}\right]\left[\mathrm{Ntf}_{2}\right]$. The same trend shift can be observed for deposition times of 15 and $60 \mathrm{~min}$ and is consistent with the literature reports. ${ }^{[25,29]}$ The trend changes along the $\left[C_{n} C_{1} i \mathrm{~m}\right]\left[\mathrm{Ntf}_{2}\right]$ series must be related to a differentiation in the molecular structure of the liquid phase around $\left[\mathrm{C}_{6} \mathrm{C}_{1} \mathrm{im}\right]\left[\mathrm{Ntf}_{2}\right](\mathrm{CAS})$ and reproduces the trend shift obtained by analyzing the thermodynamic properties of vaporization presented by Santos et al. ${ }^{[25]}$ The trend changes observed in those properties reveals the nanostructuration of this class of ionic liquids and the results obtained herein suggest that the same structural changes can be observed in the surface and wetting behavior of ILs. The existing models for the structure of ionic liquids at a molecular level consider them to be nanosegregated fluids and some authors associate the trend changes observed in several thermophysical properties with this nanosegregation. ${ }^{[44-48]}$ This class of imidazoliumbased ILs are highly structured fluids composed of high charge density areas constituted by the anions and cations (polar network) that are permeated by low-charge density regions constituted by the alkyl chains (nonpolar domains). The topology of the nonpolar domains is strongly dependent on the relative volumes occupied by the polar and nonpolar moieties of the molecules. For small alkyl side chains, the nonpolar domains are isolated islands in a continuous polar domain; for longer alkyl side chains, those islands start to coalesce and, after a certain threshold value is reached, they form a second continuous nonpolar domain. This corresponds to a kind of percolation limit of the nonpolar network areas and the creation of a bicontinuous fluid phase. ${ }^{[44-48]}$ Therefore, the trend shift observed for the number of droplets of IL formed at the ITO surface as a function of the cationic alkyl side chain size is related to the nanostructural modifications that occur around $\left[\mathrm{C}_{6} \mathrm{C}_{1} \mathrm{im}\right]\left[\mathrm{Ntf}_{2}\right]$. The analysis of Figure $3 \mathrm{~B}$ shows that the surface coverage is increased with increasing deposition time. The morphology of the micro- and nanodroplets is dependent on the IL/vacuum and IL/ITO interfacial tensions. Additionally, it is related to several factors, such as the viscosity of each $\mathrm{IL}$ and the nucleation and coalescence 
processes. The results could be compared with the surface tensions determined by Coutinho et al. ${ }^{[29]}$ According to the classical wetting theory that predicts contact angles and wetting behavior, and considering the free energy of liquid/solid-gas surfaces and the free energy of liquid-solid interface, liquids with lower surface tensions generally tend to wet solid surfaces better depending on the surface chemistry of the substrate. Nevertheless, although $\left[\mathrm{C}_{1} \mathrm{C}_{1} \mathrm{im}\right]\left[\mathrm{Ntf}_{2}\right]$ presents the highest surface tension of the series, herein the deposition of this compound results in a lower number of droplets formed by PVD and a higher surface coverage. It is important to consider that the chemical nature of the substrate and the presence of advantageous carbon have a major impact on the wetting behavior of PVD IL films. For instance, Deyko et al. reported the strong influence of carbon contamination on the growth mode of $\left[\mathrm{C}_{1} \mathrm{C}_{1} \mathrm{im}\right]\left[\mathrm{Ntf}_{2}\right]$ on a mica surface. ${ }^{[33]}$ As a possible explanation for the droplet morphology changes with chain length, the whole ITO-coated glass substrate is first wetted by one strongly adsorbed monolayer of ionic liquid and further IL is deposited onto a support with the interface, which exhibits a surface free energy that depends on the nature of this monolayer. Presumably, this interfacial free energy decreases with increasing alkyl chain lengths up to $n=6-8$. It is also important take into account that kinetics might be relevant for the process of thin-film deposition because the IL growth mechanisms might not occur in total equilibrium conditions. For example, Figure $3 \mathrm{~B}$ denotes increasing surface coverage for higher deposition times. The micro- and nanodroplets observed in this work are considered to be precursors of thin films. Thin films of ILs were obtained herein by the deposition of around $20 \mathrm{~nm}$ of gold (Au) by sputtering on the surface of the drop-lets. Figure $4 \mathrm{~A}$ presents the morphology of droplets and Figure $4 \mathrm{~B}$ presents a thin film of $\left[\mathrm{C}_{3} \mathrm{C}_{1} \mathrm{im}\right]\left[\mathrm{Ntf}_{2}\right]$ prepared by using PVD. The IL was vaporized at $\mathrm{T}=514 \mathrm{~K}$ (high mass flow rate) with a deposition time of $30 \mathrm{~min}$. The ITO surface was maintained at $\mathrm{T}=293 \mathrm{~K}$.
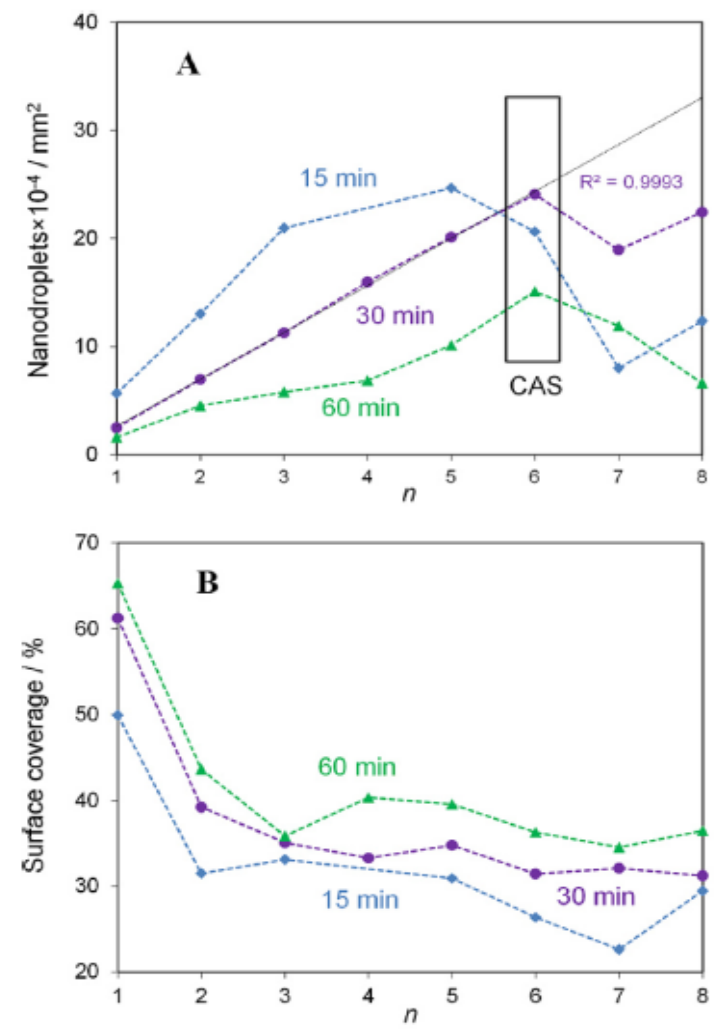

Figure 3. A) Schematic representation of the number of droplets of IL formed per $\mathrm{mm}^{2}$ of surface area by PVD for 15,30 , and $60 \mathrm{~min}$; and $\mathrm{B}$ ) representation of the surface coverage [\%] as a function of each IL in the [ $\left.\mathrm{Cn}_{n} \mathrm{C}_{1} \mathrm{im}\right][\mathrm{Ntf} 2]$ series. 
For the formation of a flat thin film, approximately $20 \mathrm{~nm}$ of Au was deposited after $3 \mathrm{~min}$ of sputtering (Figure $4 \mathrm{~B}$ ). The bombardment of energetic particles (plasma created by ionizing a sputtering gas) seems to increase the droplet mobility and coalescence mechanisms and consequently a flat thin film is obtained.

As a possibility, an Au thin film could be formed on the substrate, particularly around the IL droplets, but Figure 4B suggests that all droplets coalesced and a film of Au was deposited onto the IL surface (note that the thickness of $A u$ is very low in comparison with the size of the droplets). In addition, SEM images of IL droplets prepared on a gold surface are presented as Supporting Information. The wrinkle structures shown in Figure $4 \mathrm{~B}$ are often observed in metal films deposited on soft substrates and this can be evidence that the surface of the IL thin film is covered by a wrinkled Au thin film. ${ }^{[49]}$ In other literature reports, metal deposition onto ILs leads to particle formation within the $\mathrm{IL}^{[50,51]}$ and two-dimensionally organized gold particles formed during IL/metal sputter deposition remaining at the surface of ILs were reported only recently. ${ }^{[52]}$ The formation of flat thin films suggests the application of ILs in multilayers or mixtures (hybrid materials) with organic or inorganic semiconductors. In fact, in organic electronics and optoelectronics the interface between the semiconductor and the electrode and the interfaces between two or more thin films are crucial for charge transport and, consequently, for the efficiency of the device. ${ }^{[33-57]}$ Furthermore, the deposition of organic semiconductor (OSC) materials onto ILs and the growth of OSC crystals and/or thin films has been already reported. ${ }^{[58-}$ ${ }^{61]}$ In summary, the results of this work can contribute to the potential applications of nanodroplets and thin films of ionic liquids in organic electronics and optoelectronics and, consequently, to the development of new, green, and efficient nanotechnologies.

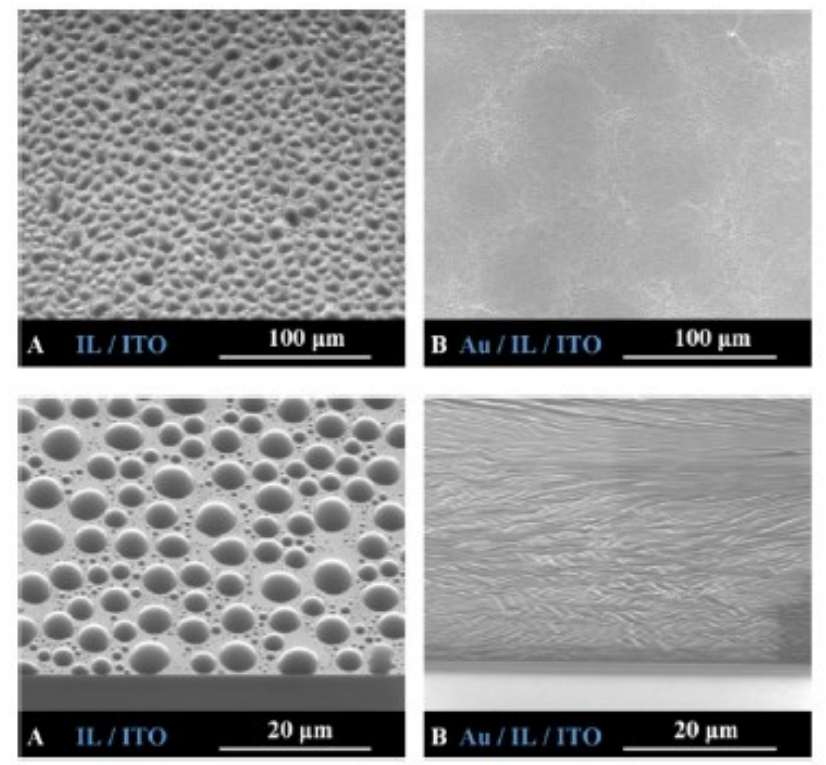

Figure 4. SEM images (top and lateral views) of nanostructures of [C3 1 im] [Ntf2] deposited on an ITO-coated glass surface by PVD: A) Droplets of IL, B) thin film of IL.

\section{Experimental Section}

The ionic liquids used herein, that is, the 1-alkyl-3-methylimidazoli-um bis(trifluoromethylsulfonyl)imide $\left(\left[\mathrm{C}_{n} \mathrm{C}_{1} \mathrm{im}\right]\left[\mathrm{Ntf}_{2}\right] ; \mathrm{n}=1-8\right)$ series, were purchased from IOLITEC with a stated purity of $>99 \%$. Before each deposition experiment, the ionic liquids were dried under reduced pressure $(<10 \mathrm{~Pa})$ and stirred constantly for a minimum of $48 \mathrm{~h}$ at $373 \mathrm{~K}$ to reduce the presence of water or other volatile content. Nanodroplets of ILs were prepared by using PVD 
with the ThinFilmVD system recently developed in our laboratory.[21] [ $\left.C_{1} C_{1} i m\right]\left[\mathrm{Ntf}_{2}\right]$, $\left[\mathrm{C}_{2} \mathrm{C}_{1} \mathrm{im}\right]\left[\mathrm{Ntf}_{2}\right],\left[\mathrm{C}_{3} \mathrm{C}_{1} \mathrm{im}\right]\left[\mathrm{Ntf}_{2}\right],\left[\mathrm{C}_{4} \mathrm{C}_{1} \mathrm{im}\right]\left[\mathrm{Ntf}_{2}\right],\left[\mathrm{C}_{5} \mathrm{C}_{1} \mathrm{im}\right]\left[\mathrm{Ntf}_{2}\right],\left[\mathrm{C}_{6} \mathrm{C}_{1} \mathrm{im}\right]\left[\mathrm{Ntf}_{2}\right],\left[\mathrm{C}_{7} \mathrm{C}_{1} \mathrm{im}\right]\left[\mathrm{Ntf}_{2}\right]$, and $\left[\mathrm{C}_{8} \mathrm{C}_{1} \mathrm{im}\right]\left[\mathrm{Ntf}_{2}\right]$ were vaporized at $\mathrm{T}=490.2,487.1,484.2,486.1,486.6,487.7,490.7$, and $495.6 \mathrm{~K}$, respectively, which correspond to a vapor pressure of $\mathrm{p}=0.1 \mathrm{~Pa}^{[25]}$ and consequently a constant mass flow rate was maintained for all compounds (the real-time mass flow rate of $\approx 3 \mathrm{ng}\left(\mathrm{cm}^{2} \mathrm{~s}\right)^{-1}$ was controlled by using a QCM for all compounds).

IL nanodroplets were prepared on a surface of ITO-coated glass (substrates were rigorously cleaned first in acetone and then in isopropyl alcohol in an ultrasonic bath and dried with an inert gas). The samples were stored in vacuum to avoid contamination and the morphology was studied by using high-resolution SEM with X-ray microanalysis and backscattered electron diffraction pattern analysis, by using a FEI Quanta400FEG/EDAX Genesis X4M instrument at 15 $\mathrm{kV}$ in low-vacuum mode at the CEMUP (Centro de Materiais da Universidade do Porto). Topographic images were acquired by using a secondary (SE) detector.

\section{Acknowledgements}

We thank the Fundação para a Ciência e Tecnologia (FCT), Lisbon, Portugal, and the European Social Fund (ESF) for financial support of the CIQ and LEPABE, University of Porto (projects: PestC/QUI/UI0081/2013, FCUP-CIQ-UP-NORTE-07-0124-FEDER-000065, UID/EQU/00511/2013LEPABE). The Centro de Materiais da Universidade do Porto (CEMUP) is also acknowledge for expert help with the SEM.

[1] M. Armand, F. Endres, R. MacFarlane, H. Ohno, B. Scrosati, Nat. Mater. 2009, 8, 621 629.

[2] F. Zhou, Y. Liang, Y. W. Liu, Chem. Soc. Rev. 2009, 38, $2590-2599$.

[3] N. V. Plechkova, K. R. Seddon, Chem. Soc. Rev. 2008, 37, $123-150$.

[4] A. Berthod, M. J. Ruiz-?ngel, S. Carda-Broch, J. Chromatogr. A 2008, 1184, 6- 18.

[5] S. A. Forsyth, J. M. Pringle, D. R. MacFarlane, Aust. J. Chem. 2004, 57, 113 - 119.

[6] W. Xu, E. I. Cooper, C. A. Anglel, J. Phys. Chem. B 2003, 107, 6170-6178.

[7] M. A. A. Rocha, C. M. S. S. Neves, M. G. Freire, O. Russina, A. Triolo, J. A. P. Coutinho, L. M. N. B. F. Santos, J. Phys. Chem. B 2013, 117, $10889-10897$.

[8] F. Dommert, K. Wendler, R. Berger, L. Delle Site, C. Holm, ChemPhysChem 2012, 13, 1625 $-1637$.

[9] O. Russina, A. Triolo, L. Gontrani, R. Caminiti, J. Phys. Chem. Lett. 2012, 3, 27 - 33.

[10] E. F. Smith, F. J. M. Rutten, I. J. Villar-Garcia, D. Briggs, P. Licence, Langmuir 2006, 22, $9386-9392$.

[11] S. Menne, J. Pires, M. Anouti, A. Balducci, Electrochem. Commun. 2013, 31, 39- 41.

[12] A. W. T. King, J. Asikkala, I. Mutikainen, P. Jarvi, I. Kilpelainen, Angew. Chem. 2011, 123, $6425-6429$.

[13] H. Liu, Y. Liu, J. Li, Phys. Chem. Chem. Phys. 2010, 12, $1685-1697$.

[14] H. O. Bourbigou, L. Magna, D. Morvan, Appl. Catal. A 2010, 373, 1- 56.

[15] F. Karadas, M. Atilhan, S. Aparicio, Energy Fuels 2010, 24, 5817 - 5828.

[16] T. Cremer, M. Killian, J. M. Gottfried, N. Paape, P. Wasserscheid, F. Maier, ChemPhysChem 2008, 9, 2185 - 2190.

[17] I. Delcheva, J. Ralston, D. A. Beattie, M. Krasowska, Adv. Colloid Interface Sci. 2015, 222, $162-171$.

[18] S. Maruyama, Y. Takeyama, H. Taniguchi, H. Fukumoto, M. Itoh, H. Kumi-gashira, M. Oshima, T. Yamamoto, Y. Matsumoto, ACS Nano 2010, 4, 5946 - 5952.

[19] T. Cremer, M. Stark, A. Deyko, H.-P. Steinruck, Maier, Langmuir 2011, 27, $3662-3671$.

[20] M. Atilhan, S. J. Aparicio, J. Phys. Chem. C 2014, 118, $21081-21091$.

[21] J. C. S. Costa, R. M. Rocha, I. C. M. Vaz, M. C. Torres, A. Mendes, L. M. N. B. S. Santos, J. Chem. Eng. Data 2015, 60, $3776-3791$. 
[22] N. Selvakumar, H. C. Barshilia, Sol. Energy Mater. Sol. Cells 2012, 98,1-23.

[23] T. W. Kelley, P. F. Baude, C. Gerlach, D. E. Ender, D. Muyres, M. A. Haase,

D. E. Vogel, S. D. Theiss, Chem. Mater. 2004, 16, $4413-4422$.

[24] C. D. Dimitrakopolos, P. R. L. Malenfant, Adv. Mater. 2002, 14, 99 - 117.

[25] M. A. A. Rocha, C. F. R. A. C. Lima, L. R. Gomes, B. Schroder, J. A. P. Cou-tinho, I. M. Marrucho, J. M. S. S. EsperanÅa, L. P. N. Rebelo, K. Shimizu, J. N. C. Lopes, J. Phys. Chem. B 2011, $115,10919-10926$.

[26] D. H. Zaitsau, A. V. Yermalayeu, S. P. Verevkin, J. E. Bara, D. A. Wallace, Thermochim. Acta 2015, 622, $38-43$.

[27] F. Rietzler, J. Nagengast, H.-P. Steinruck, F. Maier, J. Phys. Chem. C 2015, 119, 28068 28076.

[28] H.-Y. Li, T.-H. Hsu, C.-Y. Chen, M.-C. Tseng, Y.-H. Chu, Analyst 2015, 140, $6245-6249$.

[29] H. F. D. Almeida, M. G. Freire, A. M. Fernandes, J. A. Lopes-da-Silva, P. Morgado, K. Shimizu, E. J. M. Filipe, J. N. C. Lopes, L. M. N. B. F. Santos, J. A. P. Coutinho, Langmuir 2014, 30, 6408-6418.

[30] J. Luo, Y. Chen, Q. Ma, R. Liu, X. Liu, J. Mater. Chem. C 2014, 2, 4818-4827.

[31] T. Cremer, L. Wibmer, S. K. Calder?n, A. Deyko, F. Maier, H. P. Steinruck, Phys. Chem. Chem. Phys. 2012, 14, $5153-5163$.

[32] Z. Wang, C. Priest, Langmuir 2013, 29, $11344-11353$.

[33] A. Deyko, T. Cremer, F. Rietzler, S. Perkin, L. Crowhurst, T. Welton, H.-P. Steinruck, F. Maier, J. Phys. Chem. C 2013, 117, $5101-5111$.

[34] D. A. Beattie, R. M. Espinosa-Marzal, T. T. M. Ho, M. N. Popescu, J. Ralston,

C. J. E. Richard, P. M. F. Sellapperumage, M. Krasowska, J. Phys. Chem. C 2013, 117, 23676 $-23684$.

[35] M. M. Pereira, K. A. Kurnia, F. L. Sousa, N. J. O. Silva, J. A. Lopes-da-Silva, J. A. P. Coutinho, M. G. Freire, Phys. Chem. Chem. Phys. 2015, 17, $31653-31661$.

[36] R. Sedev, Curr. Opin. Colloid Interface Sci. 2011, 16, 310 - 316.

[37] J. Restolho, J. L. Mata, B. Saramago, J. Colloid Interface Sci. 2009, 340, 82 - 86.

[38] L. Gao, T. J. McCarthy, J. Am. Chem. Soc. 2007, 129, $3804-3805$.

[39] I. S. Bayer, C. M. Megaridis, J. Fluid Mech. 2006, 558, $415-449$.

[40] H. Kim, C. M. Gilmore, A. Piqu包, J. S. Horwitz, H. Mattoussi, H. Murata, Z. H. Kafafi, D. B. Chrisey, J. Appl. Phys. 1999, 86, $6451-6461$.

[41] C. C. Wu, C. I. Wu, J. C. Sturm, A. Kahn, Appl. Phys. Lett. 1997, 70, $1348-1350$.

[42] J. A. Venables, G. D. T. Spiller, M. Hanbucken, Rep. Prog. Phys. 1984, 47, $399-459$.

[43] C. Ratsch, J. A. Venables, J. Vac. Sci. Technol. A 2003, 21, S96 - S109.

[44] K. Shimizu, M. F. C. Gomes, A. A. H. Padua, L. P. N. Rebelo, J. N. C. Lopes, THEOCHEM 2010, 946, $70-76$.

[45] A. Triolo, O. Russina, H.-J. Bleif, E. Di Cola, J. Phys. Chem. B 2007, 111, $4641-4644$.

[46] J. N. C. Lopes, A. A. H. P囵dua, J. Phys. Chem. B 2006, 110, 3330 - 3335.

[47] Y. Wang, G. A. Voth, J. Am. Chem. Soc. 2005, 127, 12192-12193.

[48] S. M. Urahata, M. C. C. Ribeiro, J. Chem. Phys. 2004, 120, 1855 - 1863.

[49] S. Yu, X. Zhang, X. Xiao, H. Zhou, M. Chen, Soft Matter 2015, 11, $2203-2212$.

[50] T. Torimoto, K. Okazaki, T. Kiyama, K. Hirahara, N. Tanaka, S. Kuwabata, Appl. Phys. Lett. 2006, 89, $243117-1-3$.

[51] E. Vanecht, K. Binnemans, J. W. Seo, L. Stappers, J. Fransaer, Phys. Chem. Chem. Phys. 2011, 3, $13565-13571$.

[52] D. Sugioka, T. Kameyama, S. Kuwabata, T. Torimoto, Phys. Chem. Chem. Phys. 2015, 17, $13150-13159$.

[53] S. Kato, J. Am. Chem. Soc. 2005, 127, $11538-11539$.

[54] S. T. Lee, Y. M. Wang, X. Y. Hou, C. W. Tang, Appl. Phys. Lett. 1999, 74, $670-672$.

[55] M. Graetzel, R. A. J. Janssen, D. B. Mitzi, E. H. Sargent, Nature 2012, 488, $304-312$. 
[56] J. C. S. Costa, C. F. R. A. C. Lima, L. M. N. B. F. Santos, B J. Phys. Chem. C 2014, 118, 21762 $-21769$.

[57] J. C. S. Costa, L. M. N. B. F. Santos, J. Phys. Chem. C 2013, 117, 10919-10928.

[58] Y. Takeyama, S. Maruyama, Y. Matsumoto, Cryst. Growth Des. 2011, 11, $2273-2278$.

[59] Y. Takeyama, S. Maruyama, H. Taniquchi, M. Itoh, K. Ueno, Y. Matsumoto, CrystEngComm 2012, 14, 4939 - 4945.

[60] Y. Takeyama, S. Mantoku, S. Maruyama, Y. Matsumoto, CrystEngComm 2014, 16, 684 689.

[61] S. Horike, Y. Koshiba, M. Misaki, K. Ishida, Jpn. J. Appl. Phys. 2014, 53, 05FT03 -1 - 4. 